\title{
El dispositivo de poder como medio de comunicación: Foucault - Luhmann
}

\author{
Raúl ZAMORANO FARÍAS \\ Centro de Estudios Teóricos y Multidisciplinarios en Ciencias Sociales - Universidad Nacional \\ Autónoma de México \\ rzamorano61@gmail.com \\ Rosario ROGEL-SALAZAR \\ Facultad de Ciencias Políticas y Sociales - Universidad Autónoma del Estado de México \\ rosariorogel@gmail.com
}

Recibido: 18-05-2012

Aceptado con modificaciones: 14-03-2013

Aceptado: 18-04-2013

Resumen: El objetivo central de este artículo es identificar las posibles prestaciones analíticas entre dos autores cuyas propuestas teóricas parecieran distantes: Michel Foucault y Niklas Luhmann. Se analiza no sólo la forma en que opera el dispositivo/diferencia que históricamente genera rela-ciones de poder, sino también se explora cómo opera en su manifestación discursiva, en su di-ferenciación como medio de comunicación o, en la construcción de sentido como régimen dis-cursivo preguntando, en concreto ¿qué es lo que opera/comunica el poder?

Palabras claves: genealogía del poder, dispositivo de poder, teoría general de sistemas sociales, medios de comunicación simbólicamente generalizados

\section{The power dispositif as a mean of communication: Foucault-Luhmann}

\begin{abstract}
The aim of this paper is to identify the possible analytical provisions between two authors whose theoretical proposals might seem very distant: Michel Foucault and Niklas Luhmann. We analyze not only how the dispositif/difference that generates power relations operates, but also how it operates on its discourse manifestation, on its difference as a communication mean or in the construction of meaning as a discursive regime by asking specifically: what does the power communicate/operate?
\end{abstract}


Key words: Genealogy of knowledge, power dispositif, general theory of social systems, symbolically gene-ralized media

\section{Referencia normalizada}

Zamorano Farías, R. \& Rogel-Salazar, R. (2013). "El dispositivo de poder como medio de comunicación: Foucault - Luhmann”. Política y Sociedad, Vol.50 Núm. 3 959-980

Sumario: Introducción. 1.Foucault: de la arqueología del saber a la genealogía del poder. 2.La sociología de Luhmann y el código poder. 3.Vínculos analíticos Foucault-Luhmann. Bibliografía

Llevar el problema al plano de las formas y valores, como coartada y sustituto funcional, siempre deviene más oportuno aunque menos interesante y, por cierto, teóricamente del todo improductivo...

Nexus

\section{Introducción $^{1}$}

La evolución del concepto 'tiempo' impone una nueva reflexión acerca de los sistemas de percepción, observación y entendimiento de lo que denominamos realidad. A partir del reconocimiento ya no de una, sino de varias y simultáneas perspectivas de interpretación, nos enfrentamos a una realidad abierta a lo que no es imposible y tampoco necesario (contingencia).

Desde hace algunos años, es ya lugar común escuchar referencias a la llamada ‘crisis de los grandes paradigmas' como parte de la reacción frente a la hegemonía cultural y científica del dogmatismo racionalista y tecnológico de la modernidad de la sociedad (Calello y Neuhaus, 1995); poniendo en tela de juicio las perspectivas analíticas que explicaban los fenómenos sociales remitiendo a un centro o factor determinado (Luhmann, 2007). Las construcciones tradicionales de orden social y las viejas estabilidades naturales ligadas al pasado dejaron de ser pertinentes para explicar y observar la modernidad de la sociedad y del actual orden social. La génesis de las incertidumbres en torno a dicho proyecto quizá pueda remontarse a las reflexiones del Nietzsche post-kantiano, pasando por las propuestas de fenome-

${ }^{1}$ Este artículo tiene su origen en un trabajo originalmente presentado por el Dr. Raúl Zamorano Farías en el Coloquio Michel Foucault: un cuarto de siglo después (UNAM, 2 de septiembre , 2010), y se inscribe en el Proyecto "Procesos de diferenciación en la periferia de la sociedad moderna: el sistema político en México”, Conacyt CB-131060 (2011) en el cual participan ambos autores. 
El dispositivo de poder como medio de comunicación: Foucault - Luhmann

nología trascendental de Husserl y la fenomenología hermenéutica antiontoteleológica heideggeriana. ${ }^{2}$

Todo ello tiene fuertes implicaciones en la teoría de la sociedad moderna que, abandonada a sí misma se enfrenta, continuamente, a las improbabilidades estructurales adquiridas con la evolución. Y, sin embargo, resulta sumamente interesante que, pese a reconocer la crisis de los paradigmas que parten de concebir la realidad como única e inmutable, se siga reflexionando sobre la base teórica de una estructura social premoderna, onto-teleológica, trascendental o retórica prescriptiva. ${ }^{3}$ Así, pese a las transformaciones y cambios en la forma de producir lo social, todavía se sigue pensando y fundamentando a las relaciones sociales, políticas o de poder desde la figura de la subordinación, de la sujeción de lo particular a lo general.

Es sabido que las perspectivas críticas sobre la modernidad buscan problematizar criterios de verdad que se han establecido canónicamente y que impiden dar cuenta de los cambios que se producen en la sociedad; sin preguntarse, por ejemplo, cómo se absorbe la contingencia y se recrean las tensiones esenciales en la modernidad de la sociedad moderna, y entre ellas el problema del poder. ${ }^{4}$ Dicho en otras palabras, la crítica a la sociedad moderna ha dejado intacta la pregunta acerca de cómo se produce y cómo opera la tensión entre consenso y conflicto en las estructuras y semánticas del poder contemporáneo (véase Luhmann, 1997).

Tal que hemos arribado a un punto en el que los artefactos teóricos interesados en analizar el orden social, el poder, el sujeto 'perdido', la realidad pre-escrita y el conocimiento verdadero y único se refuerzan y constituyen en una elegante -pero improductiva- forma moderna para el trato con contingencias; prescindiendo de plantearse incluso la pregunta de si lo designado -aquello de lo que se habla‘existe' o no (Luhmann, 1997, p. 95, 99, 105).

Todo lo contrario, aún se piensa que en la sociedad hay relaciones cuasi-lineales -entre ellas el poder- que existen sólo si hay subordinación, ese lazo indisoluble

${ }^{2}$ El trabajo de Nietzsche representado en las obras que escribió a partir de 1874 como Así hablaba Zaratustra; La gaya ciencia; y, Humano demasiado humano. De Husserl, básicamente, sus Investigaciones lógicas (publicado en 1913) enfocadas al estudio científico de las estructuras básicas de la conciencia humana, y la obra de Heidegger representada fundamentalmente por Ser y Tiempo (publicado en 1927), donde critica la idea de la superación del sujeto en el espacio y el tiempo como expresión del dogmatismo racionalista y tecnológico que caracteriza la modernidad en crisis y derrumbe, frente a lo cual sólo es posible colocar al pensamiento en una actitud de superación de un pasado que no significa.

${ }^{3}$ La obra de Niklas Luhmann se nos presenta como el mayor intento sociológico de superar definitivamente la metafísica moderna (véase la primera parte de Luhmann, 2007).

${ }^{4}$ Entre dichas perspectivas destacan la famosa triada que conforma la "teoría de la sospecha” (Karl Marx, Friedrich Nietzsche, Sigmund Freud), las reflexiones de la escuela de Frankfurt (con Jürgen Habermas como heredero), el postmarxismo (Cornelius Castoriadis), así como la genealogía de Michel Foucault, o la crítica de Peter Sloterdijk a la "razón cínica”. 
entre técnica y razón. A ello se suman posturas que observan las relaciones de poder proyectadas en el tiempo como un mecanismo capaz de controlar el futuro, aun cuando ese poder no reconozca siquiera la arquitectura analítica de su historia. Precisamente, uno de los problemas que cruza toda la producción de lo moderno es el de las nuevas estructuraciones y circuitos del problema del poder, así como la disolución de las grandes concentraciones de poder que suponía la teoría clásica y en donde, por tanto, era fácil la elaboración del discurso sobre el poder (metarrelatos). Genealogía, posesión, materialidad y comunicación del problema del operar de un poder que ya no tiene rostro y que, además, opera en el espacio pequeño (recordemos que este fue uno de los temas centrales de la Escuela de Frankfurt). ${ }^{5}$

Lógicamente, lo anterior significa repensar la semántica, las estrategias que describen y autodescriben el dispositivo poder. Observar esta comunicación, este dispositivo en la modernidad de la sociedad moderna, toda vez que la institución poder es precisamente una institución generada por la modernidad ilustrada y articulada, originalmente, al amparo de conceptos como Estado, historia, finalidad, revolución, reforma, clase, libertad, sujeto, obediencia y telos. Improntas tardoilustradas de la concepción poder que denotan, al menos, cuatro grandes rasgos:

- El vínculo social del poder que se articula con fundamento en 'la razón';

- La 'localización' del poder en instancias superiores que lo regulan;

- La potencialidad del poder en tanto instancia crítica; y,

- El potencial regulador del poder que libera el conflicto.

Sin embargo, la gravedad histórica de la crisis y los resultados constitutivos de los efectos del poder dejan de manifiesto que éste ya no puede reconocerse en sus supuestos rasgos fundamentales. El gran malestar de nuestro tiempo está determinado por el resquebrajamiento y por las consecuencias en la apropiación de poder para fines particulares. Esta determinación, entre otras cosas, bloquea el fundamento de la soberanía y acrecienta el divorcio entre la legalidad formal del poder y los hechos constitutivos del dispositivo poder. ${ }^{6}$ Lo anterior no significa que los mecanismos que producen poder no continúen operando sino, simplemente que los

${ }^{5}$ Los teóricos de la escuela de Frankfurt, desde el modelo de la seria y buena cultura burguesa, del romanticismo, del psicoanálisis, del humanismo marxista, ofrecen una nueva lógica y sensibilidad creativa, opuesta a la manipulación de la conciencia, una sociedad donde la verdad y la voluntad son formaciones cooperativas a través del lenguaje libre que posibilita el consenso racional (Habermas). Sobre esto véase, entre otros a Rubert de Ventós, 2004, p. 81-82.

${ }^{6}$ Sobre todo en la actualidad, cuando se constata que el "mundo de la vida” (Habermas, 1991, p. 416-419) ha perdido el significado que antaño poseía para comprender las relaciones y estructuras sociales. 
conceptos ya no pueden sostener los supuestos que lo fundamentan, haciendo imposible que la modernidad pueda releerse y autodescribirse a sí misma. ${ }^{7}$

¿Cuáles son entonces los supuestos que soportan el concepto 'poder', si cuando éste se intenta localizar parece estar siempre en otro lado?

Orientado por estas preocupaciones, Michel Foucault -considerado el filósofo de la historia real y efectiva- articula una arquitectura analítico-descriptiva en la que busca analizar la relación poder-saber. ${ }^{8}$ Foucault se sitúa en una posición pragmática, una actitud descriptiva que congele toda pretensión de validez ex-ante y, desde ahí, describir lo que se ve (o, más propiamente, lo que él dice ver). Para él, la microfísica supone que el poder que en ella se ejerce no se concibe como una propiedad, sino como una estrategia; por ello, sus efectos de dominación no pueden ser atribuidos a una "apropiación", sino a disposiciones, maniobras, tácticas y técnicas. Todo ello le lleva a concluir que el poder, más que poseerse se ejerce (Foucault, 1996, p. 33).

Así, Foucault ofrece una descripción, una construcción científica de cómo opera el poder, toda vez que parece no valorar la necesidad de fundamentar una distinción tajante entre ciencias del espíritu y ciencias de la naturaleza. Quizá porque, como él mismo reconoce, no está interesado en construir una propuesta teórica general del poder, sino más bien en estudiar su arqueología y consecuente genealogía. Es decir, pretende estudiar ese mecanismo que nos atraviesa, modela nuestros cuerpos y comportamientos, se mete en nuestra vida cotidiana y comparte incluso nuestras camas y hasta los sueños, como señala Foucault (1996, p. 50, 51). ${ }^{9}$

${ }^{7}$ Sabido es que los clásicos de la sociología han cimentado las bases de la disciplina, y eso no hay quien lo dude. Pero la única forma de construir sobre esa base consiste en atreverse a romper con la continuidad del pensamiento clásico, cuando éste ya no resulta fructífero para el análisis de fenómenos que no pudieron ser observados cuando los padres de la sociología reflexionaron sobre la sociedad de su época (al respecto véase, Luhmann, 1992).

${ }^{8}$ La obra de Michel Foucault registra una clara transición entre lo que él mismo denomina “arqueología” hacia el “análisis genealógico”. Este cambio se advierte en una preocupación que se traslada del plano de los discursos, manifiesto en obras como Historia de la locura, El nacimiento de la clínica y Las palabras y las cosas, escritos entre 1950 y finales de la década de los años sesenta; al interés por analizar de las formas de dominación, tal como se advierte en Microfísica del poder, Vigilar y castigar y La historia de la sexualidad, escritos a partir de 1969. No obstante, la continuidad entre ambas etapas se encuentra en el análisis de la relación saber-poder. Al respecto, véase también Arqueología del Saber (publicado originalmente en 1969) donde, como el mismo autor señala, no se ofrece una síntesis ni repetición de lo escrito por él anteriormente; sino que aporta críticas internas a su propia propuesta (Foucault, 1979, p. 27).

9 Esa "neutralidad valorativa" a la que se refiere Weber. Precisamente, es sobre estas bases que Habermas, el filósofo de la moralität (basada en el consenso), articula su crítica contra las grandes indagaciones de Foucault: presentismo, relativismo y un camuflado normativismo. Una crítica que Habermas funda en Las palabras y las cosas, texto que el mismo Foucault reconoce como un primer intento descriptivo de los tipos de problemas y 
Desde otra perspectiva, la teoría general de los sistemas sociales de Niklas Luhmann agrega elementos que enriquecen el debate sobre la problematización y el estudio del orden, la estructura social y su relación con la semántica del poder. ${ }^{10}$ Para Luhmann es necesario, por un lado, superar la conceptualización clásica del poder $y$, por otro, asumir que deviene operativamente más satisfactorio considerar al poder como a cualquier otro medio de comunicación, como algo que limita la gama de selecciones del otro (Luhmann, 1995, p. 17). ${ }^{11}$ Antes bien, el poder ha de ser entendido como una comunicación dirigida por un código. Como consecuencia de esto, la función del poder no queda adecuadamente descrita si se piensa que consiste simplemente en movilizar al subordinado a aceptar las órdenes de un superior (concepción negativa que también Foucault confronta).

Precisamente, es necesario distinguir el poder de la obligación, de la coerción, de esa violencia que llevaría a actuar de una manera determinada y concreta. El poder no tiene un carácter negativo natural. Al límite, la coerción conduce a la violencia física y, con ella, a la sustitución de la acción deseada y no conseguida, por la acción violenta. Sin embargo, el ejercicio de la violencia evidencia precisamente la incapacidad de poder. Para Luhmann el poder no es el instrumento de una voluntad ya presente, es el poder el que genera -produce diría Foucault- esa voluntad. El poder puede hacer demandas, puede obligar a absorber riesgos e inseguridades, incluso puede llevar a la tentación y dejarla frustrada (Luhmann, 1995, p. 31).

En tal sentido, el objetivo de este artículo es identificar las posibles prestaciones analíticas de Michel Foucault y Niklas Luhmann, mediante el análisis no sólo de la forma en que opera el dispositivo/diferencia que históricamente genera relaciones de poder, sino también explorando cómo opera en su manifestación discursiva.

\section{Foucault: de la arqueología del saber a la genealogía del poder}

Las investigaciones tanto archivísticas como de teoría social de Foucault tienen como eje central la relación saber-poder, un tema que -desde su perspectiva- no ha sido plenamente analizado. De ahí que en su trabajo no busque repetir 'qué es el poder', ni construir metodológicamente una nueva teoría sobre él. Intenta plantear un giro epistemológico, problematizando cómo se articulan y operan sus mecanis-

tipos de discurso que interesa analizar en su arqueología del saber. Al respecto, véase el interesante trabajo de Borch, 2005.

${ }^{10}$ La teoría general de los sistemas sociales es una teoría de diferenciación social y de evolución social y cultural que conduce a una diferenciación creciente; donde los medios de comunicación pueden constituirse cuando la forma de selección de Alter al mismo tiempo sirve como estructura motivacional de Ego (Luhmann, 1995, p. 8).

${ }^{11}$ Los medios de comunicación son mecanismos adicionales al lenguaje. Son códigos de símbolos generalizados que guían la transmisión de selecciones (Luhmann, 1995, p. 11). 
mos generadores para, finalmente, preguntarse cómo se genera el poder, cómo la 'voluntad de verdad' constituye 'voluntad de poder y sentido' (Sinn).

Al igual que Luhmann, Foucault establece un cambio en la pregunta del qué al cómo, del 'deber ser' a 'la construcción de sentido'. Con ello se reorienta la cuestión acerca de 'qué es el poder', hacia la investigación de 'cómo se produce y de qué manera se ejerce’. Es decir, se preguntan ¿cómo opera el dispositivo/diferencia que genera históricamente relaciones de poder?, y ¿qué comunica?

En este sentido -y desde la semántica luhmanniana- es dable sostener que a Foucault le preocupa observar cómo se formaliza/construye socialmente ese sentido, cómo opera el dispositivo que constituye y experimenta el saber-poder. Sin embargo, es claro que la genealogía analítica del fenómeno histórico de Foucault es completamente diferente a la arquitectura sociológica formulada por Luhmann. ${ }^{12} \mathrm{Y}$ es claro también que a ambos les interesa problematizar la mecánica operativa del poder (y la constitución del sujeto/persona social). Analizar cómo opera en su manifestación discursiva, en su diferenciación como medio de comunicación o, en la construcción de sentido como régimen discursivo superando -como ha señalado Foucault- la teleología causal.

Teleología causal frente a la cual Foucault plantea la cuestión del dispositivo y sus productos (poder), en un intento crítico por sacar a la luz, por observar la constitución y formación histórica de los sistemas de poder. Una crítica ya no fundada en la exégesis, repetición y culto a los muertos, sino en el estudio del pasado, en el análisis retrospectivo, en la historia real, la historia efectiva, narrada en términos de conflicto y de poder desde nuestro tiempo; ${ }^{13}$ desde la modernidad de la sociedad moderna. ${ }^{14}$

${ }^{12}$ Aun considerando las evidentes diferencias y rendimientos teóricos, en Foucault y Luhmann se reconocen similares perspectivas epistemológicas: diferencia, construcción, observación de segundo orden, comunicación. Sugerimos revisar el texto de Borch (2005), quien retoma el análisis y conceptualización del poder en Foucault, para llevar a cabo una revisión crítica de la teoría del poder de Luhmann. De igual forma, destaca el trabajo de Pottage (1998, p. 2) quien -en una actitud crítica hacia las interpretaciones más comunes del concepto de poder en Foucault- propone una lectura a la luz de la teoría general de sistemas sociales de Niklas Luhmann, donde concluye que el poder es una figura forma de desdiferenciación de la diferencia.

${ }^{13}$ Como ejemplo de ello puede señalarse todo lo realizado hasta el paroxismo por los 'marxólogos' sobre la obra de Marx (como agudamente señala Foucault, 1992), o volver a resucitar una y otra vez a los clásicos (como señala Luhmann, 2007).

${ }^{14}$ A riesgo de que las semánticas a través de las cuales se describe esta historia sigan a distancia de tiempo las transformaciones estructurales de la sociedad; piénsese, por ejemplo, en el drama, en la farsa de la política contemporánea de los derechos (¡humanos!), de la opinión retórica que al no encontrar un lenguaje que posibilite observar, establecer diferencias y analizar, se sigue reproduciendo a través de lenguajes cosificados, arcaicos, morales u ontológicos. "Los problemas de la sociedad moderna no se definen como problemas de 
A partir de su inicial arqueología del saber, Foucault llega a una genealogía del poder, que le permite revelar cómo la objetivación de la razón -y sus regímenes de verdad y conocimiento que se constituyen en saber- se acoplan de un modo histórico y contingente. Así, Foucault se da a la tarea de analizar corpus de conocimiento literario, médico, religioso, policial, ético; no para encontrar la verdad de la historia, sino para mostrar cómo el saber es portador de poder.

"No basta con decir que el poder tiene necesidad de éste o aquél descubrimiento, de ésta o aquélla forma de saber, sino que ejercer el poder crea objetos de saber, los hace emerger, acumula informaciones, las utiliza [...] El ejercicio del poder crea perpetuamente saber e inversamente el saber conlleva efectos de poder” (Foucault, 1992, p. 99).

Y si bien, para Foucault, poder y saber están estrechamente vinculados, también reconoce que no por ello dejan de ser diferentes; su vínculo de coincidencia se da en el discurso y en razón de ello la transferencia entre ambos no puede totalizarse; es imprevisible pues que el ámbito discursivo que hace posible dicho vínculo, funciona al mismo tiempo como obstáculo y como resistencia. El entramado que teje el vínculo saber-poder parte así de segmentos discursivos discontinuos, cuya función no es uniforme ni estable y puede actuar en sentidos opuestos. Por esta razón, para emprender una genealogía del poder, el sociólogo francés se interesa por analizar las condiciones materiales del discurso: indaga la constitución de instituciones como la prisión, el hospital, la escuela; estudia discursos judiciales, médicos, educativos; pero analiza, sobre todo, las estrategias de poder que los "cuerpos dóciles" adoptan con relación a las instituciones. A todo este entramado de relaciones lo denomina "microfísica del poder".

Las conclusiones a que arriba Foucault $(1996,1979)$ le permiten afirmar que ningún poder se ejerce sin la apropiación o retención del saber y en ello, el papel que juegan las estrategias discursivas son determinantes. Los “cuerpos dóciles" son posibles gracias a la disciplinarización que se ha introyectado históricamente; al "cuidado de sí" instaurado por las instituciones normalizadoras (escuela, iglesia, moral cristiana) que, una vez secularizadas, son reemplazadas por el saber científico como locus del saber y del valor. ${ }^{15}$

mantenimiento del origen (ontos). (...) Se trata más bien de una constante producción de otredad" (Luhmann, 1997, p. 17).

${ }^{15}$ En este sentido, y para continuar con el ejemplo mencionado acerca del reclamo contemporáneo por reconocer los derechos humanos, vale la pena recordar lo que Foucault señala en la introducción a El Antiedipo: capitalismo y esquizofrenia de Deleuze y Guattari (en su edición estadounidense): no es preciso pedirle a la política que restaure los derechos del individuo tal como han sido definidos por la filosofía pues, dado que el individuo mismo es producto del poder, lo que sería preciso es “desindividualizar” por medio de multiplicación y dislocación, mediante diversas combinaciones (véase Foucault, 1999). 
Más tarde, si bien Foucault continua sosteniendo que todas las relaciones sociales se caracterizan por el poder y la resistencia, empieza a enfocar su interés en la distinción entre poder y dominación, que no es otra cosa que la consolidación de las relaciones de poder que limita los espacios de libertad y resistencia; para concluir que todos los individuos son a la vez dominados y dominadores. El poder es, entonces, concebido como organización positiva de la vida y no como mera represión: el poder es relacional. Con el tiempo, Foucault fue desplazando el énfasis desde las "tecnologías de dominación” hacia las "tecnologías de sí mismo”, desde la forma en que los individuos son transformados por otros hacia los modos en que ellos se transforman a sí mismos (véase Foucault, 1979). ${ }^{16}$

En términos generales, es posible afirmar que a Foucault no le interesa el análisis de los problemas en lo particular, ${ }^{17}$ toda vez que el "estudio de caso" en sí no agota -y no tiene por qué agotar- la problematización analítica y el desmontaje de las relaciones, tramas e imbricaciones históricas en las cuales opera el dispositivo. ${ }^{18}$ Incluso, a decir de Gilles Deleuze, para Foucault el intelectual "ha dejado de ser universal para tornarse específico, es decir, que no habla ya en nombre de unos valores universales, sino en función de su propia competencia y de su situación” (Deleuze, 1995, p. 123), cuando no de su ideología. ${ }^{19}$

${ }^{16}$ Analizar cómo ha sido posible que en ciertos momentos y en ciertos órdenes de saber existan estos despliegues básicos, estas precipitaciones de evolución, estas transformaciones que no corresponden a la imagen tranquila y continuista que se tiene habitualmente (Foucault, 1992, 188).

${ }^{17}$ Y si bien a Foucault no parece haberle interesado la descripción de fenómenos particulares en sí mismos, sino la manera en que determinados procesos se inscriben en una cadena de sucesos que permiten delinear la genealogía del poder; muchos de sus seguidores parecen estar interesados en la descripción de fenómenos que permitan "comprobar” -sin cuestionar- el funcionamiento de lo que advierten como 'dispositivos de poder', ya sea en la escuela, en la política e incluso en la equitación (como ejemplo basta remitir al programa del Coloquio "Michel Foucault: un cuarto de siglo después", UNAM, 2010, disponible en: http://cetmecs.blogspot.com/2010/08/coloquio-internacional-michel-foucault_16.html).

${ }^{18}$ Orientado por la forma en cómo opera este dispositivo, estudiar, por ejemplo, las formas de exclusión social, a los excluidos, al ritual de la exclusión que, incluso, termina por acoplar las formas de exclusión incluyéndolas productivamente en las relaciones sociales: universidad, escuela, hospital, cárcel (véase la entrevista de J. K. Simon de 1971, publicada originalmente en la Revista Partisan y reproducida en Foucault, 1992). En igual dirección se orienta Luhmann cuando propone estudiar y distinguir las formas en que se da la formalización del sentido y sus operaciones, exclusiones e inclusiones. Inclusiones que -como ironiza Sloterdijk (2006) - serían precisamente el elemento discursivo que constituye la conciencia cínica ilustrada de nuestro tiempo.

${ }^{19} \mathrm{Si}$ esas disposiciones desaparecieran tal como aparecieron; si, por cualquier acontecimiento - cuya posibilidad podemos cuando mucho presentir, pero cuya forma y promesa no conocemos por ahora- oscilaría el suelo del pensamiento clásico como lo hizo a fines del 
Incluso, 'escandalosamente’ Foucault no busca ni está detrás de un sujeto “ontológico” constituyente - del 'sujeto perdido’- para fundamentar su análisis. Más bien lucha por desembarazarse de 'ese' tipo de sujeto. En su lugar, se interesa por articular un análisis que permita dar cuenta de la constitución del sujeto, no del sujeto constituyente, sino del sujeto constituido precisamente por y en el interior de una trama de relaciones normadas y reglamentadas (dispositivos). ${ }^{20}$

En este punto, conviene recordar que, si por algo es conocida la propuesta teórica de Niklas Luhmann, es, justamente, por el escándalo que suscita su abandono de la sujetología y la moral trascendental, como fundamento de la constitución del sistema social. De hecho, en ello consiste una de las principales criticas que le atribuye Habermas y en razón de ello lo descalifica por desarrollar un planteamiento neoconservador (véase Luhmann, 1997). Bien, pues resulta sumamente interesante advertir que justo uno de los propósitos de Foucault es descentrar y erradicar el concepto moderno de sujeto unificado y racional, mediante una arqueología y genealogías criticas que reducen al sujeto a un efecto del discurso y de las prácticas disciplinarias, no es gratuito pues que también Habermas lo haya calificado de neoconservador (véase Habermas, 1991, capítulos IX y X).21

Históricamente, como se ha señalado, el poder fue pensado como coerción/represión. En la teoría moderna del poder, éste fue considerado como una relación de exterioridad -localización-, en conformidad a la verdad. Es en esta exigencia de conformidad, en la cual encontramos la relación de exterioridad, donde la política articula poder y verdad. Tal que, desde la concepción clásica el poder conserva una relación de exterioridad con respecto a la verdad. Se asume entonces

siglo XVIII, y entonces quizá podría apostarse a que el hombre se borraría, como en los límites del mar un rostro de arena (Foucault, 1995, p. 375).

20 "Llegar a un análisis que pueda dar cuenta de la constitución del sujeto en la trama histórica”. Eso que Foucault llama genealogía; es decir: "una forma histórica que da cuenta de la constitución de los saberes, de los discursos, de los dominios objeto" (Foucault, 1992, p.191-192). Problematización y análisis del discurso y de sus diferentes tipos de articulación histórica de normas y de reglas. En este sentido, Foucault -pese a su crítica- es también un estructuralista, sobre todo en sus primeros escritos.

${ }^{21}$ Sin lugar a dudas, afirmar que la sociedad no está hecha de sujetos, sino de comunicación (Luhmann); o bien, la apuesta por descentrar y erradicar el concepto moderno de sujeto unificado (Foucault) son cuestiones que suscitan múltiples discusiones. Y si bien ello podría ser altamente productivo, el objetivo de este artículo es "analizar la forma en que opera el dispositivo/diferencia que históricamente genera relaciones de poder, y explorar cómo opera en sus manifestaciones discursivas”. Esto, sin pretensión de anular al sujeto, o de someterlo al mero discurso; sino simplemente de instalarlo como una construcción y, luego de eso, observar la forma en que -en tanto construcción semántica- diversos autores puedan advertir posibilidades analíticas del concepto “sujeto”. Lo cual sería objetivo de otro artículo. 
El dispositivo de poder como medio de comunicación: Foucault - Luhmann

que el poder está en el Estado. ${ }^{22}$ Foucault, por el contrario, entiende que las cuestiones relativas al Estado, las leyes, o las formas de dominación son sólo expresiones terminales del poder, cuya función ideal será ligar el placer, la coerción y la verdad, y no exclusivamente vigilar y castigar. No sólo la coerción o el castigo.

Cuáles son y cómo operan entonces esas relaciones entre deseo, poder e interés en una situación singular, sobre todo cuando el poder no puede ser ya concebido como una sustancia, como una cosa, como un ser/entidad que se posee y transmite, que se intercambia a suma cero ('lo que doy de poder lo gana otro'). Si el poder no fuera más que represivo, se pregunta Foucault, sería plausible sostener que, realmente, se le obedecería. No. Lo que hace que al poder se le acepte es simplemente que no pesa solamente como una fuerza que dice no, sino que produce cosas, induce placer, forma saber, produce discursos (Foucault, 1992, p. 192-193).

Es sobre la base de estos postulados que Foucault, en su intento de dar cuenta de la sociedad disciplinaria (burguesa), aborda el problema de la función del poder como una "red productiva" que atraviesa todo cuerpo social; donde el problema de la política es, precisamente, sancionar el uso legítimo de la fuerza más allá de la instancia negativa que sólo ostenta la "función de reprimir" (Foucault, 1992, p. 193). De ahí que el teórico francés insista en que las funciones del poder serían la verdad, el placer y la coerción -y no sólo la coerción o el sometimiento-, en una situación donde la estrategia/poder relacional es siempre configurada provisionalmente (un evento en la gramática luhmanniana), toda vez que cuando no sea necesario ejercer la fuerza (violencia: Luhmann) se estará frente a una operación ideal del poder (una eficiencia máxima del poder: el panóptico).

A partir de ello Foucault cuestiona los postulados de la visión moderna sobre el poder, pues no se trata de una propiedad: el poder no se posee, se ejerce, es una estrategia que está permanentemente en juego. ${ }^{23}$ Por otro lado, el poder no está

${ }^{22}$ Relación donde el Estado caracterizaría las diferencias entre lo legal e ilegal, encarnando la localización del poder, en donde además la verdad siempre pre-existe al poder. (Foucault, 992).

${ }^{23}$ A juicio de Foucault, Nietzsche viene a repotenciar una concepción de poder -como relación de fuerza- que ya Maquiavelo había planteado. En relación con la genealogía de la historia -voluntad-, para Nietzsche la reflexibilidad como autocomprensión del sujeto, es la figura de cómo se diseña la historia -el tema de la historia es el hombre- (antropomorfismo), lo cual significa que la trama de la historia, es la trama del sentido de la existencia. Darle un sentido a la historia y a la existencia es darle finitud. No se trata que la historia sólo tiene sentido con el hombre, sino, supone que éste satisface la voluntad de conocerlo todo (la búsqueda de la verdad animada por el dolor allí en donde lo que angustia al hombre no es el dolor mismo sino el carácter aparentemente sin sentido del dolor). Si el misterio del dolor no está resuelto, nada está resuelto (sobre esto véase Nietzsche, 1980). 
El dispositivo de poder como medio de comunicación: Foucault - Luhmann

localizado en un lugar determinado (Estado). ${ }^{24}$ Para decirlo de otra manera, el poder no es otra cosa que el nombre dado a una relación, a una comunicación, y es precisamente desde la microfísica que es posible entender sus localizaciones. En este sentido, Luhmann no está lejos de Foucault cuando se refiere al carácter mediático del poder. Poder en tanto una comunicación orientada por un código (véase Luhmann 2007, capítulo II).

Para Foucault un poder que sólo se limita a decir “no”, no puede ser considerado poder efectivo, en tanto al mismo tiempo no ejerza cierto deseo/placer de aquello que reprime. Es por ello que no se trata ya tanto de denunciar cuanto de analizar cada uno de los discursos (legal, pedagógico, médico, universitario, político) desde la trama de las relaciones que lo constituyen, porque el producto poder no es el conjunto de instituciones y aparatos que garantizan la sujeción del ciudadano a un Estado, ni el sistema de dominación ejercido por un grupo o una clase sobre otros. Es un mecanismo omnipresente no porque tenga el privilegio de reagruparlo todo bajo su invencible unidad, sino porque se está produciendo a cada instante, en todos los puntos, o más bien en toda relación de un punto con otro. El poder está en todas partes; no es que lo englobe todo, sino que viene de todas partes (Foucault, 1979). ${ }^{25}$

Desde esta perspectiva, es dable sostener que el poder no es causa de la conducta; sino básicamente un mecanismo para regular selecciones contingentes. Una multiplicidad de relaciones de fuerza inmanentes al dominio en que se ejerce, un conjunto de relaciones no externas a los procesos económicos, al conocimiento o a las relaciones sexuales, que no se adquiere, ni se arranca, ni se comparte, un poder que viene de todas partes. Consecuentemente, se diluye la oposición binaria entre dominadores y dominados; por tanto deviene inútil buscar el estado mayor que preside la racionalidad del poder, ni la casta que gobierna, ni los grupos que controlan los aparatos del Estado. Donde hay poder hay resistencia, por eso mismo ésta no es exterior al poder, incluso cuando dichas resistencias puedan formar un reverso siempre cínicamente pasivo, condenado a la derrota infinita. ${ }^{26}$

${ }^{24}$ Deslizando, implícitamente, una crítica a la concepción revolucionaría de la toma del poder, del Estado, puesto que si el poder ya no se posee ni está localizado en el "Palacio de invierno" qué sentido tiene la revolución..., con o sin nieve.

${ }^{25}$ Poder que para Foucault está y constituye la frontera de todo lo social. En la semántica de Luhmann el poder puede leerse como un mecanismo que opera en todo medio de comunicación simbólicamente generalizado: verdad/valores, amor, dinero, poder/derecho (véase Luhmann, 1995 y 2007).

${ }^{26}$ Mas, si el poder está en la frontera de todo lo social ¿dónde están los “espacios/pliegues, bucles" de libertad? A decir de Foucault, radican en los espacios de no dominación absoluta; respuesta que no deja de ser sorprendente por el vínculo a una ontología que él mismo parece rechazar. De su análisis se deriva que, para evitar la perversión del poder (dominación), sería preciso recurrir a reglas del derecho, a técnicas racionales de gobierno, a la ética de la libertad. Sin embargo, y siguiendo la lógica foucoultiana, paradójicamente aun cuando sea posible conocer el origen histórico de los conceptos políticos que 
Ahí podría radicar la sombra que opaca el modelo edificado por Foucault pues, en su arqueología y genealogía de las prácticas y discursos modernos, tal propuesta deviene un aparato ideológico que permite transformar el impulso más subversivo y disolvente del criminal y del esquizofrénico en un logogrifo estructuralista de la inmanencia del poder. Con este modelo se suprime el conflicto, mas no por mediación dialéctica -a la manera hegeliana- sino por sustitución y trasposición -a la manera freudiana-; entre el significado dominante y el significado revelado por medio de una decodificación del significante. En Foucault el poder parece estar y definir las fronteras de todo lo social. Como las máscaras de un prestidigitador, los signos aparecen y desaparecen ocultando siempre la cara, en la que el poder emerge desmigajado en un número infinito de fragmentos entrelazados que paradójicamente imposibilitan su observación y operación (al respecto véase Bartra, 1981).

\section{La sociología de Luhmann y el código poder}

Luhmann considera su teoría sociológica una teoría científica, esto es, una teoría desarrollada en el seno del sistema de la ciencia . Pero ello, sin duda, supone una concepción muy particular de lo que es una teoría científica. En esta propuesta el sujeto es reemplazado por el observador y el objeto por lo observado, pero no se trata ya más de un observador que -como una placa fotográfica- limita su acción a la mera pasividad, al simple hecho de dejarse impresionar por el objeto observado (Rodríguez-Mansilla, 1995, p. IX). Tampoco existe un superobservador científico poseedor de la verdad absoluta, definitiva.

Su propuesta teórica tiene por tanto la pretensión de ser aplicable a cualquier fenómeno social, sin aspirar exclusividad y menos reclamar para sí la posición única de observador último, sino más bien orientarse a la producción teórica de formulaciones conceptuales que crean y generan nuevas condiciones de observación y análisis reflexivo de la realidad social. Planteamiento teórico que se aleja radicalmente del consenso y de la 'descripción de descripciones' buscando superar la impotencia intelectual de un permanente deber ser que, en última instancia, nos deja siempre más cerca de la moral y de la ideología que de la reflexión científica (Luhmann, 2007).

Luhmann se plantea como objetivo describir y conceptualizar a la sociedad, con conocimiento pleno de lo que esto implica epistemológica y metodológicamente. Lo cual significa sustituir las ideas clásicas sobre la causalidad sistémica y descartar, también, la supuesta existencia de estructuras sociales constantes. Así, mientras el posestructuralismo, los nuevos estudios culturales y la antropología, la 'desconstrucción’, la teoría de la información y los estudios tecnológicos en general siguen

usamos, difícilmente sería posible regular su uso, incluso a través del ejercicio del poder (formaciones discursivas). 
describiendo a la sociedad, Luhmann pone el acento en las diferencias, en la autorreferencia, la autopoiesis, los acoplamientos estructurales de los sistemas que la forman. Así, entonces, en cómo es posible el orden social. Es decir, al teórico alemán le preocupa observar y describir cómo opera y qué hace al sistema, cuáles son las operaciones que lo distinguen y constituyen, y también cómo estas operaciones permanecen o cambian, pero sin buscar soluciones o predicciones apriorísticas en lo inmediato, orientadas a controlar y/o intervenir las prácticas sociales.

El resultado es que, en su propuesta teórica, no hay una búsqueda de etéreos principios de causalidad o finalidad. Hay una observación de las distinciones que comunican y, en tanto son comunicadas, operan sentido. Pues, lógicamente, las operaciones son las que conforman el mundo de lo social. La sociedad es un sistema autorreferente, un sistema que puede crear su propia estructura y los elementos de que se compone, con su propio programa de comunicaciones que lo reproducen. Es decir, un sistema que autogenera sus propios elementos constituyentes. Tal que, como paradigma de la teoría de los sistemas sociales, la diferencia entre sistema y entorno obliga a sustituir la diferencia todo-partes, por una teoría de la diferenciación sistémica (Luhmann, 1990, p. 53-54). ${ }^{27}$

Los sistemas sociales se construyen a partir de la comunicación y ésta sólo tiene lugar cuando la selectividad de una notificación es entendida y puede ser utilizada para la selección de un estado propio del sistema. ${ }^{28}$ Los sistemas sociales se forman siempre a través de formalizar la comunicación, en tanto y cuanto necesidad de selección que impone la evolución y la progresiva diferenciación. No obstante, es importante considerar que los medios de comunicación simbólicamente generalizados no pueden restringirse ni aislarse en sistemas parciales.

En el contexto de la complejidad social destacan dos elementos fundamentales en la operación y estructura de poder: la centralidad de la comunicación para observar los hechos históricos y el problema de cómo la comunicación sobre el poder puede llegar a politizarse. Todos los sistemas sociales son conflictos en potencia, y sólo varía la medida de la actualización de ese potencial, con el grado de diferenciación sistémica y con la evolución societal. Los medios de comunicación pueden constituirse cuando la forma de selección de Alter al mismo tiempo sirve como estructura motivacional de Ego (Rodríguez-Mansilla, 1995, p. XXII).

En esta lógica, para la teoría general de los sistemas sociales, las articulaciones/operaciones comunicativas de la sociedad no están dadas por el consenso nor-

${ }^{27}$ A partir de esta radical constatación fenomenológica se construyen las bases epistémicas que guían la arquitectura teórica propuesta por Luhmann, uno de cuyos puntos de arranque es la necesaria formalización del sentido (medio), como diferencia entre lo que es y no es, entre lo que se excluye o incluye, entre aquello que se observa y lo que no puede ser observado (Luhmann, 2007).

${ }^{28}$ Observación que no reclama un metalenguaje pues el observador constituye la observación en tanto que designa algo, con lo cual lo designado (marcado) aparece precisamente como aquello que es (Luhmann, 1997, p. 93). 
El dispositivo de poder como medio de comunicación: Foucault - Luhmann

mativo; el orden social se construye sobre la base de la disyunción entre conducta conforme y conducta desviada y la correspondiente diferenciación de expectativas y reacciones, en relación con el medio de comunicación simbólicamente generalizado: poder. En ese proceso también está siempre presente el riesgo o la posibilidad de rechazo, el conflicto, ya que potencialmente, todos los sistemas sociales son conflictivos. Lógicamente, el grado en que se realiza este conflicto potencial varía de acuerdo con el grado de diferenciación del sistema y de acuerdo con su evolución social (Luhmann, 1995 y 2007).

Luhmann observa que para la concepción weberiana, el poder es una acción que genera un efecto frente a una resistencia esperada. Ello supone un esquema causal que puede producir efectos, lo que implica un sujeto de la acción. Dichos esquemas causales son sistemas ficticios; es decir, son construcciones que seleccionan algo, atribuyéndole algo de la realidad para explicar los efectos. De esta forma, el poder, desde el esquema causal, muestra que estas construcciones son esquemas de atribución cambiante.

La tesis fundamental de Luhmann es que el poder requiere formalizarse en diferentes formas rígidas (frente al poder laxo), para que adquiera contornos más específicos. ${ }^{29}$ Esta rigidización del poder posibilitará la conformación del sistema político, cuyo medio específico es el poder (pero no todo poder es político). ${ }^{30}$ Sin embargo, el poder en sí mismo es muy inestable, por lo tanto tiende a perder rigidez. La sanción negativa no opera en el sentido de facto sino en la potencia, en la expectativa que disuelve la resistencia del otro. Dicho en otras palabras, el poder opera en la expectativa de la amenaza, el poder se mueve en esta lógica (Luhmann 1995). ${ }^{31}$

Precisamente, para Luhmann, una suposición fundamental de todo poder es que la inseguridad existe en relación con la selección del alter que tiene poder. Por diferentes razones, alter tiene a su disposición más de una alternativa, por lo tanto puede producir y quitar inseguridad en su compañero cuando ejerce su elección. Esta desviación por la vía de la producción y reducción de la inseguridad es una precondición absoluta del poder, estipula la latitud que existe para la generalización

${ }^{29}$ En este sentido, Luhmann marca una diferencia fundamental con la concepción de Foucault, para quien el poder está y constituye la frontera de todo lo social.

${ }^{30}$ El poder social puede manifestarse bajo tres dimensiones (formas de influencia): $\mathrm{Po}$ der como autoridad que absorbe inseguridad (aspecto constitutivo de la comunicación). En toda la sociedad, y sus sistemas, se manifiesta este tipo de poder avalado en el conocimiento. Poder positivo, formas modernas de organizar el poder positivamente para movilizar y desarrollar procesos. Se manifiesta típicamente en las organizaciones mediante la sanción positiva. Poder político que opera mediante sanción negativa.

${ }^{31}$ El poder no es negativo, en tanto cuanto que, como poder, presupone la aceptación o rechazo de configuraciones frente a ofertas comunicativas. La noción negativa y represiva del poder evidencian, precisamente, la ausencia de poder y la presencia de la materialidad física (Luhmann, 1979, p. 69-80). 
y especificación en un medio de comunicación determinado, mas no constituye por sí mismo una fuente de poder particular. ${ }^{32}$

Al respecto, Luhmann señala que es necesario distinguir el poder de la obligación, de la coerción, de la violencia que lleva a actuar de una manera determinada y concreta. En el caso límite, la coerción conduce a la violencia física y, con ella, la sustitución de la acción deseada por la acción violenta. No obstante, el ejercicio de la violencia demuestra simplemente la incapacidad de poder, toda vez que, para Luhmann, la causalidad del poder se basa en la neutralización de la voluntad del otro y no necesariamente en someter esa voluntad.

Esta noción mediática del poder es concebida dentro de una teoría de la evolución social según la cual, el ejercicio del poder es una entre varias formas funcionalmente equivalentes de manejar la creciente complejidad.

Entendido como una comunicación dirigida por un código, el poder es un importante medio de comunicación simbólicamente generalizado que se relaciona con la complejidad reducida, que transmite complejidad, y orienta condiciones específicas de aplicación. Como consecuencia de esto, la función del poder no queda adecuadamente descrita si se piensa que consiste simplemente en movilizar al subordinado a aceptar las órdenes del superior. Como señala Luhmann, el poderoso también debe movilizarse para ejercer su poder y en esto radica, a menudo, la mayor dificultad. El subordinado ha de estar capacitado para elegir su propio comportamiento y, por lo tanto, ha de poseer la posibilidad de autodeterminación; sólo por esta razón se le aplican medios de poder, tales como las amenazas o sanciones, con el objeto de dirigirlo en esta elección propia. ${ }^{33}$

Precisamente, en esto consiste la función del poder, en asegurar las cadenas posibles de efectos, independientes de la voluntad del participante sujeto al poder. El poder, como todo medio de comunicación, es una oportunidad para aumentar la probabilidad de realización de combinaciones improbables de selecciones. Por ello, el poder sólo se entiende como un medio de comunicación simbólicamente generalizado. Los medios de comunicación sólo se originan en el nivel de lo que se supone es el vivir junto con otros cuando la influencia es contingente y, con eso, al fin, más

32 Toda comunicación tiene lugar en la sociedad y la reproduce, pero esto no implica una comunicación a-problemática, ideal, razonable y consensual; sino precisamente una comunicación que puede ser conflictiva, irracional y conducir al disenso, aunque en todos estos casos contribuya a la preservación de la autopoiesis del sistema. El medio de comunicación poder limita la gama de selecciones del otro. Aun cuando el poder puede realizarse en otros sistemas sociales ocasionalmente, según sus necesidades, este es un medium específico del sistema político y es allí donde se reproduce (Luhmann, 1995, p. XXI y Corsi et al., 1996, p. 126-127).

${ }^{33}$ El rechazo comunicado en respuesta y traducido en un tema dentro de los sistemas sociales, se identifica con el conflicto. Cuando se postula un poder absoluto, se trata de un poder escaso y limitado, porque en él no hay situaciones de elección de Ego en las que Alter pueda influir (Luhmann, 1995, p. 9). 
bien improbable. Sólo cuando, y en tanto que, los bienes son escasos, el reclamo activo de algunos de ellos, por parte de una persona, se convierte en un problema para otros. Esta situación se regula a través de un medio de comunicación, el que transfiere la acción seleccionada por la persona a la experiencia de los otros y ahí la hace aceptable (Luhmann, 1995, p. 19-20).

Tal vez, la diferencia más importante, con respecto a las teorías del poder más antiguas, es que la teoría de los medios de comunicación conceptualiza el fenómeno del poder sobre la base de una diferencia entre el código y el proceso de comunicación (no como un "ser" o "entidad", sino más bien como una construcción, en el mismo sentido que señala Foucault) y, por lo tanto, en una operación que no está en posición de atribuir poder a una de las personas como propiedad o facultad. ${ }^{34}$ De este modo, el poder no se convierte en el instrumento de una voluntad ya presente; antes que nada genera esa voluntad (Foucault). Los símbolos generalizados del código, los deberes e insignias del cargo y las ideologías y condiciones de legitimación sirven para ayudar al proceso de articulación, pero el proceso mismo de comunicación sólo cristaliza motivos cuando está ejerciendo el poder.

Por tanto, para Luhmann, el poder no es un artefacto completamente autosuficiente, sino que depende de otros factores, tanto para las condiciones que lo hacen posible como para su nivel de demanda y necesidad (Luhmann, 1995, p. 31-85). ${ }^{35}$ Así, en términos de la circunstancia factual tanto como en términos del tiempo, no es sorprendente que en las comunicaciones de poder existente -incluso desde un punto de vista social- se manifiesten tensiones y síntomas críticos. Incluso el sistema político parece no ser capaz de tratar lo que se requiere para llevar a cabo las operaciones de toma de decisiones y de transmisión. Dicho en otras palabras, esto significa que el poder constituido políticamente como un sustituto técnico unificado para la autoridad, la reputación y el liderazgo es inestable y falla.

Como señala Luhmann (1995, p. 136), en la actualidad, las debilidades del poder en el contexto de la evolución societal son obvias. Fundamentalmente, éstas se reflejan en el intento -sin dejarse eliminar por éste- de reemplazar la comunicación a través del poder con la comunicación sobre el poder. Sin embargo, en vista de la etapa de adquisiciones evolutivas que ha alcanzado la sociedad, el hecho de volver a bases más naturales para la generalización de la influencia, difícilmente forma parte del asunto, en lo que respecta a la producción y operaciones del poder. ${ }^{36}$

${ }^{34}$ El poder se distingue de otros medios de comunicación, toda vez que su código supone que existen personas en ambos lados de la relación de comunicación, quienes reducen la complejidad a través de la acción, y no sólo a través de la experiencia (Luhmann, 1995, p. 22-27).

${ }^{35}$ Lo cual requiere que el poder desarrolle una codificación secundaria, que vaya más allá del binomio superior/inferior. Tal codificación será aportada por el sistema del derecho: legal/ilegal (Luhmann, 1995, p. 92 y Corsi et al., 1996).

${ }^{36}$ En esta articulación Luhmann indica que la autoridad es la influencia temporalmente generalizada, el liderazgo corresponde a la influencia circunstancialmente generalizada. La 


\section{Vínculos analíticos Foucault-Luhmann}

Luhmann supera la explicación ontológica porque no asume que exista en el mundo un lugar desde el que pueda describirse correcta (o falsamente) el mundo tal cual es (Luhmann, 2007, p. 55-63 y 108-129). La ontología ya no tiene lugar después de la muerte de Dios, como aún promulgan las valoraciones trascendentales u ontológicas de las teorías del sujeto o de teorías "críticas", al estilo habermasiano (donde, de paso, se ahorran, incluso, tener que exponer los propios intereses: la ideología) (Luhmann, 1996, p. 255). Luhmann es radical: la modernidad ha muerto definitivamente, y las categorías que los teóricos de la sociedad utilizaban para comprender el hecho social son inútiles (Luhmann, 2007). Desde otra perspectiva, pero en igual dirección, Foucault viene a fracturar el pensamiento social moderno, no busca justificar la modernidad, sino instalar intersticios (saber-poder), abrir nuevos espacios a la reflexión, a la crítica que cuestiona la función del discurso.

Sabido es que el análisis de las comunicaciones/dispositivos de poder, que cristalizan el conflicto, ha orientado el esfuerzo de la teoría social por encontrar una explicación a este fenómeno, pero en "general en el tratamiento sociológico que se le da al conflicto se analiza sólo la parte destructiva: el aniquilamiento de los cuerpos, el incendio de las casas, el exterminio de la humanidad” (Luhmann, 1996, p. 245, 247). En esta lógica, la característica teórica más importante es su dependencia en un número de suposiciones acerca de la causalidad: prominente ejemplo de cómo el poder y la causalidad son conceptualizados en la teoría clásica sobre el poder (Luhmann, 1995, p. 148- 150).

Pero las cosas no son sino el discurso (sentido, significación), como señala Foucault, y también el cómo se organiza ese discurso epocal para definir la representación de la realidad desde donde se construyen precisamente formas de vida.

En la arquitectura teórica de los sistemas sociales, la observación de estas formas de construcción de lo social es realizada siempre por el sistema con ayuda de diferencias, de esquemas de observación creadas por el sistema, y ello supone un momento de inseguridad, incertidumbre, relatividad, incluso arbitrariedad que choca frontalmente con los estándares de las teorías de la ciencia clásica, especialmente con el de certeza intersubjetiva. En este sentido, como al Foucault de Las palabras y las cosas, a Luhmann le interesan las operaciones fácticas, lo eminentemente material, pues ya no se trata que, desde la sociología, se pueda "decidir sobre Dios, sobre la justicia, sobre la educación o sobre la optimización del principio de unidad", más aun "cuando en una sociedad funcionalmente diferenciada falta la autori-

autoridad se crea sobre la base de una diferenciación de probabilidades debido a una acción previa. La reputación se basa en la suposición de que pueden darse razones para la corrección de la influencia. El liderazgo se basa en un deseo cada vez mayor de seguir, estimulado por la percepción que otros también están siguiendo; en otras palabras, se basa en la imitación (Luhmann, 1995, p. 107-109 y 121). 
dad que se podría obtener del estar situado en una metaposición” (Luhmann, 1996, p. 266). ${ }^{37}$

Foucault, en su analítica del poder, se ocupa de problemas que son notablemente similares a las preocupaciones de Luhmann. Ambos autores critican la teoría clásica del poder (potencia imagen) en tanto sustancia que puede ser poseída. El problema, señala Luhmann, es que una simple referencia a la posesión del poder, donde el poder se transfiere de una persona a otra y de una situación a otra, oculta totalmente las condiciones sistémicas de dicha modalidad/operación de poder. Adicionalmente, esto hace suponer que el ejercicio del poder es un juego de suma cero donde, cada vez que un poder se lleva a cabo se genera la correspondiente pérdida de poder. No obstante, una teoría adecuada debe ser capaz de tener en cuenta que la energía aumenta a menudo en un lugar, sin que ello conduzca a una pérdida paralela en otros lugares.

Tanto para Foucault como para Luhmann, precisamente, lo que hay que superar, en la teorética del poder, es el discurso de la soberanía o la concepción jurídicopolítica de éste. Superar la vieja idea que ha conceptualizado al poder como una sustancia que puede ser poseída, intercambiada o localizada, lo cual va en la misma dirección -entre otras cosas- de la idea luhmanniana de un poder como juego de suma cero. Por ello, la necesidad de superar el supuesto de la ubicación del poder que postula, en general, que éste se concentra en un centro específico, en el monarca o el aparato del Estado, desde donde fluye de arriba hacia abajo al resto de la sociedad.38 Esto es particularmente evidente en la importancia por atribuirle al poder las prohibiciones y las leyes para que el poder -y siempre según el modelo jurídico-político- sea esencialmente la oposición a la libertad. Por su parte, Foucault habla de estructuras o de mecanismos de poder en tanto supone relaciones entre individuos (o entre grupos), no en un juego de suma cero, sino simplemente en un entramado de acciones que inducen a otras acciones y que se concatenan entre sí (Foucault, 2011).

A pesar de que la estructura social, que sostenía esta concepción del poder, pereció hace mucho, la noción negativa, jerárquica, del poder prevalece en el pensamiento social contemporáneo dominante, tanto en la cabeza de liberales cuanto de libertarios marxistas. Sin embargo, si la sociedad moderna es sobre todo funcionalmente diferenciada (Luhmann), los medios de comunicación simbólicamente generalizados no pueden restringirse ni aislarse en sistemas parciales; es decir, la verdad no puede tener un rol exclusivo en la ciencia, como tampoco el poder tiene un rol exclusivo de la política. Dondequiera que las personas se comuniquen entre sí, es

${ }^{37}$ Es por ello que no se puede observar el "mundo" desde "fuera del mundo" (y de forma total o privilegiada). Y tampoco desde el centro del universo, como señaló Gramsci (a menos, claro, que exista Dios).

${ }^{38}$ Especialmente el poder político, en donde el discurso de la soberanía se basa precisamente en el argumento de que el poder sirve para fines de represión. 
probable que se orienten hacia la posibilidad de un conflicto, de un perjuicio mutuo (Luhmann, 1995, p. 127).

Al respecto, Foucault sostiene que debemos dejar atrás la noción negativa jerárquica del poder pues ésta no se basa en argumentos sociológicos. Además, la agresividad del sistema político no es el único problema a largo plazo, en relación con las fuentes de poder que existen en toda sociedad más extensa; también está el problema de mantener la especificación funcional de los diferentes sistemas para que sean sistemas diferentes (Luhmann, 1995, p. 131). Diferenciación funcional en subsistemas funcionalmente autónomos como la política, el derecho, el arte, la religión, lo cual implica que la sociedad moderna no tiene un vértice o centro (Luhmann, 1990, p. 23-30 y 2007).

Por tanto, una tal caracterización sugiere la necesidad de sustituir las nociones de poder y renunciar a la pretensión por volver a instalar una concepción de sociedad jerárquicamente ordenada y totalizante; sobre todo cuando, empíricamente, la sociedad es diferenciada (policéntrica) y, consecuentemente, las interdependencias, cada vez mayores, multiplican las supuestas fuentes de poder, que ya no pueden controlarse políticamente. El retiro, el retraso, o incluso, solamente, las acciones no cooperativas de descontento que puedan necesitarse en alguna parte, se convierten en una estrategia, en una plausibilidad mayor de poder que no recurre a la violencia física, ni puede combatirse por medio de amenazas de violencia física. Precisamente, ése es el problema, porque cualquier cosa de este poder que se presente y exija dominio se excluye y debilita paulatinamente su capacidad para funcionar (Luhmann, 1995, p. 132).39

Toda voluntad de verdad (sentido) es voluntad de poder y orden. El sentido no sólo hace posible la comprensión de la historia, sino también su realización. El sentido es la relación de la conciencia con lo que es posible, lo posible a partir de ahora. Entonces, un problema central que está detrás de los diferentes tipos de órdenes y su evolución histórica (como proceso, lucha de clases, malestar de la cultura, evolución jurídica, imaginarios simbólicos) es el problema del “poder”, sus nuevas (y viejas) estructuras -el discurso ético y sus fundamentos puestos en crisis, el problema de la genealogía y arqueología (Foucault), de la comunicación del poder (Luhmann)-, que nos obligan precisamente a problematizar la relación orden/poder, como una operación y no como una entidad.

En consecuencia, la producción, la diferenciación, la generalización y la especificación funcional de los medios de comunicación sirven para aumentar la discrepancia entre lo posible y lo actual, y esto no sólo en el sentido de aumentar la selectividad en los procesos, sino también en la creación estructural de expectativas

${ }^{39}$ Bajo postulados propuestos normativamente como la democracia, la participación o la co-determinación, todos los tipos de sistemas organizacionales en todos los contextos funcionales sociales, ya sean escuelas, minas, prisiones o parroquias, son confrontados con demandas de participación en el ejercicio del poder (Luhmann, 1995, p. 136). 
exageradas y de exigencias sobre las capacidades de los sistemas de comunicación correspondientes (Luhmann, 1995, p. 123); sobre todo cuando el problema no es que un sujeto/persona haga historia, el problema es que otros también hacen historia. He ahí el conflicto: toda praxis contempla la praxis del otro, como en un juego de ajedrez (Wittgenstein).

En la sociedad de la sociedad moderna y en su modernidad existen un conjunto de fuerzas que definen, que dan movimiento (es la novedad la que da movimiento a la sociedad: Luhmann). Nuestra realidad no está ordenada, es emergente, desregularizada, contingente. Novedad y actualización devienen conceptos centrales no para deber ser, sino para ser haciendo, pues buscamos la regularidad. La emergencia genera dispositivos; es decir, una organización que define y positiviza, establece un orden del caos (racionalización que define una práctica). Y ahí, toda nuestra vida se encierra en juegos de verdad, donde siempre es posible relativizar las verdades y no reducirlas a mera falsedad (Foucault, 1992).

Ello es posible sobre la base de distinciones y diferencias que permiten a la sociedad generar descripciones que van más allá de verdades unívocamente históricas y, por tanto, universales; dejando abierta la pregunta de cómo esto sea posible aun cuando improbable, como señala Luhmann.

\section{Bibliografía}

Bartra, Roger. 1981. Las redes imaginarias del poder político, Serie Popular Era 79, Distrito Federal, México.

Borch, Christian. 2005. "Systemic Power Luhmann, Foucault, and analytics of power”, en Revista Acta Sociológica, vol. 48, núm. 2, Universidad Nacional Autónoma de México, Distrito Federal, México, pp. 155-167.

Calello, Hugo y Susana Neuhaus (comps.). 1995. Las vicisitudes del método en la sociedad delirante, Oficinas de publicaciones del ciclo básico común, Universidad de Buenos Aires, Buenos Aires, Argentina.

Corsi, Giancarlo; Elena Esposito y Claudio Baraldi. 1996. Glosario sobre la teoría social de Niklas Luhmann, Anthropos - Universidad Iberoamericana - Instituto Tecnológico y de Estudios Superiores de Occidente, Distrito Federal, México.

Deleuze, Gilles y Félix Guattari. 1985. El Antiedipo: capitalismo y esquizofrenia, Ediciones Paidós Ibérica, Barcelona, España.

Deleuze, Gilles. 1995. Conversaciones 1972-1990, Pre-textos, Valencia, España.

Foucault, Michel. 1979. Arqueología del saber, Editorial Siglo XXI, Distrito Federal, México.

Foucault, Michel. 1979. Historia de la sexualidad I La voluntad de saber, Editorial Siglo XXI, Distrito Federal, México. 
Foucault, Michel. 1992. Microfísica del poder, ediciones de la piqueta, Madrid, España.

Foucault, Michel. 1995. Las palabras y las cosas, Siglo XXI editores, Distrito Federal, México.

Foucault, Michel. 1996. Vigilar y Castigar, editorial Siglo XXI, Distrito Federal, México.

Foucault, Michel. 1999. "Prefacio: una introducción a la vida no fascista”, Estrategias de poder, Obras esenciales volumen II, Paidós, Barcelona, España, pp.385388.

Foucault, Michel. 2001. "El sujeto y el poder” en Michel Foucault: más allá del estructuralismo y la hermenéutica, Hubert L. Dreyfus y Paul Rabinow (coords.), Nueva Visión, Buenos Aires, Argentina.

Habermas, Jürgen. 1991. El discurso filosófico de la modernidad, editorial Taurus, Madrid, España.

Heidegger, Martin. 1993. Ser y Tiempo, Editorial Universitaria, Santiago de Chile, Chile.

Husserl, Edmund. 1999. Investigaciones Lógicas, vols. I y II, Alianza Editorial, Madrid, España.

Luhmann Niklas. 1979. Potere e complessità sociale, Il Saggiatore, Milán, Italia.

Luhmann Niklas. 1992. "El ocaso de la sociología crítica”, Separata de la Revista Universidad de Guadalajara, Guadalajara, México.

Luhmann, Niklas. 1990. Sociedad y sistemas: la ambición de la teoría, Paidós Institut de Ciències de l'Educació, Universitat Autònoma de Barcelona, Barcelona, España.

Luhmann, Niklas. 1995. Poder, editorial Anthropos, Barcelona, España.

Luhmann, Niklas. 1996. “'De que se trata el caso' y 'qué es lo que se esconde detrás’: Las dos sociologías y la teoría de la sociedad”, en Introducción a la teoría de sistemas, Universidad Iberoamericana, Distrito Federal, México.

Luhmann, Niklas. 1997. Observaciones de la modernidad. Racionalidad y contingencia en la sociedad moderna, Paidós Studio, Barcelona, España.

Luhmann, Niklas. 2007. La sociedad de la sociedad, editorial Herder, Distrito Federal, México.

Nietzsche, Friedrich. 1980. Así hablaba Zaratustra, Editorial Edaf, Madrid, España.

Nietzsche, Friedrich. 1996. Humano, demasiado humano, Editorial Edaf, Madrid, España.

Nietzsche, Friedrich. 2002. La gaya ciencia, Editorial Edaf, Madrid, España.

Pottage, Alain. 1998. "Power as an art of contingency: Luhmann, Deleuze, Focucault" en Economy and Society, vol. 27, núm. 1 (febrero), Routledge, pp. 1.27

Rodríguez-Mansilla, Darío. 1995. "Nota a la versión en español”, en Poder de Niklas Luhmann, editorial Anthropos, Barcelona, España.

Rubert de Ventós, Xavier. 2004. Por qué filosofía, editorial Sexto Piso, Distrito Federal, México.

Sloterdijk, Peter. 2006. Crítica de la razón cínica, editorial Siruela, Madrid, España. 